\title{
Dealing with customers enquiries simultaneously under contingent situation
}

\section{Sujan Piya*}

Department of Mechanical and Industrial Engineering, College of Engineering, Sultan Qaboos University, AL-Khod 123, Muscat, Sultanate of Oman

\begin{tabular}{l}
\hline C H R O N I C L E \\
\hline Article history: \\
Received September 142014 \\
Received in Revised Format \\
January 102015 \\
Accepted February 102015 \\
Available online \\
February 112015 \\
\hline Keywords: \\
Quotation \\
Contingent order \\
Negotiation \\
Make-to-Order
\end{tabular}

\section{A B S T R A C T}

\begin{abstract}
This paper proposes a method to quote the due date and the price of incoming orders to multiple customers simultaneously when the contingent orders exist. The proposed method utilizes probabilistic information on contingent orders and incorporates some negotiation theories to generate quotations. Rather than improving the acceptance probability of quotation for single customer, the method improves the overall acceptance probability of quotations being submitted to the multiple customers. This helps increase the total expected contribution of company and acceptance probability of entire new orders rather than increasing these measures only for a single customer. Numerical analysis is conducted to demonstrate the working mechanism of proposed method and its effectiveness in contrast to sequential method of quotation.
\end{abstract}

(C) 2015 Growing Science Ltd. All rights reserved

\section{Introduction}

Companies that operate in Make-to-Order (MTO) environment must respond to enquiries by preparing quotations that are attractive to their customers and feasible for them to fill. Dealing properly with customers enquiries has a huge impact on orders being confirmed by the customer. Lots of researchers have contributed to the area of quotation. However, from the relevance of industrial domain, due date and price quotation are the most researched areas. With an objective of minimizing expected aggregate cost per job, Seidman and Smith (1981) have proposed a method to identify due date for incoming order. On the other hand, Bertrand (1983) and Baker (1984) have considered the objective of minimizing the average weighted due date quoted to the customers. Ragatz and Mabert (1984), Shantikumar and Sumita (1988), Wein (1991) and Chand and Chhajed (1992) have advocated that due date based on shop-floor congestion information achieves better delivery performance. Most of these researchers have dealt with due date and/or pricing decisions under a single-product and single-stage production system. Enns (1995) and Van and Bertrand (2001) have investigated the setting of cost optimal internal due dates for determining the priorities on the shop floor, and in determining the external due dates that can be quoted to the customer. Lawrence (1995) has developed a model for due date estimation using empirical distribution of forecasted error in production settings with machine breakdowns. Elhafse (2000) has proposed exact and heuristic algorithms for determining the lead-time and price to be quoted to a single order by dividing total orders into regular and rushed orders. Proposing two different models, Keskinocak

* Corresponding author.

E-mail: sujan@squ.edu.om (S. Piya) 
et al. (2001) has shown that different strategies for quotation are needed for different categories of customers. Charnsirisakskul et al. (2006) has presented an optimization model for due date and price sensitive customers under deterministic demand function. Liu et al. (2007) has considered pricing and lead-time decisions from a supplier-retailer perspective where demand is deterministic and sensitive to price and lead-time decisions. Similarly, Kaminsky and Kaya (2008) have developed due date quotation model in the supply chain environment where the model is affected by the performance of supplier. Based on the result of empirical analysis, Zorzini et al. (2008) has proposed a method of quoting due date that took into account the known average lead time. Slotnick (2011) has presented stochastic dynamic programming model for lead time quotation for a production system in which bottleneck process requires a minimum batch size. Chaharsooghi et al. (2011) has extended the model of Charnsirisakskul et al. (2006) to include multi class customers with stochastic demand. Recently, Xianfei et al. (2013) has studied production scheduling problem with an objective of maximizing profit when customers are sensitive to quoted delivery time.

When an enquiry about new order arrives, the company may already have several orders either in the form of confirmed orders or contingent orders. The time between customer enquiry and order acceptance (OA) decision can be extremely long and exhaustive enquiry may, unfortunately, not be converted into confirmed order. As a matter of fact, the completion time and production costs required to fill new order that arrive, when contingent orders exist, cannot be anticipated with any degree of precision. This complicates matters for company that have to prepare quote for new order. Easton and Moodie (1999) is the first paper to explicitly coin the effect of contingent orders on quotation. The paper dealt with this problem in a single resource and single job production environment. The same problem was later expanded into a multiple job environment with different routines for each job by Cakravastia and Takahashi (2003). To prepare quotation for different class of customer under contingency environment EDD and FCFS method of scheduling was utilized in Watanapa and Techanitisawad (2005a). Further, Watanapa and Techanitisawad (2005b) have proposed GA based quotation method where limited number of tardy jobs is allowed. In the same line of research, Corti et al. (2006) has developed analytical tool to compare capacity requirement of order pool, including contingent orders, with respect to actual capacity of shop floor. All these papers have defined contingent orders as potential orders that were awaiting customer confirmation on whether to accept or reject quotation submitted by company. These papers utilized S-shaped logit model to calculate the probability of quotation being accepted by new customer. The model was constructed without utilizing any probabilistic information on contingent orders. Also, as contingent orders are a source of uncertainty in capacity, these papers fail to propose appropriate strategy to hedge against this uncertainty in case contingent order cannot be converted into confirmed order.

Quotation represents initial phase in OA decisions (Sujan et al., 2009). OA decisions, in MTO systems, are often the consequence of negotiations between the customer and the company over contested issues (Moodie and Bobrowski, 1999). Sujan et al. (2009) has proposed a method that can simultaneously quote the due date and the price by implementing the concept of negotiation margin. Further, defining contingent order as a customer engaged in negotiation with a company to reach an agreement, Piya et al. (2009b) has proposed a probabilistic method with a negotiation structure to counter the uncertainty created by contingent orders and prepare quotes for a new order. All these mentioned papers with contingent orders have considered generating quotation only for single customer at a time. However, once new customer makes an inquiry, there will be some time lapses before the company prepares quotation and submit it. Within the lapsed time, other new customers may arrive in the systems for an inquiry. In such situation, the company has to prepare quotation for the customer under the influence of uncertainties created by both the contingent orders and the other new orders. To cope with such circumstances, this paper proposes a method that can prepare quotations simultaneously for multiple new customers. The method aims to increase the probability of quotations being accepted by their customers. To the best of author's knowledge, this is the first paper to consider the research on quotations for multiple customers simultaneously under contingency effect. The method will first tackle the effect of contingent orders and then generate quotations for multiple customers simultaneously. 
The rest of the paper is structured as follows. Section 2 describes the problem that will be addressed in this research. Section 3 explains the proposed method in detail. Section 4 discusses and presents the results of the numerical analysis. Finally, concluding remarks and future research directions are highlighted in section 5.

\section{Problem Description}

This paper reflects the method of quotation as a function of negotiation between the company and the customers of contingent orders. In MTO systems, once customer has arrived with some technical specifications, the company is asked to give quote, which basically will be on the due date and the price. After submitting quotation, the customer and the company may engage in negotiations to reach an agreement, if the quoted value is not acceptable to the customer. Negotiations begin with a customer counter-offering another due date and/or price against the quotation submitted by the company. Such orders represent contingent orders in this paper. The negotiations may continue for several rounds during which the company proposes new offer on due date and/or price and the customer opposes it by counteroffering another due date and/or price within their limit levels. In an attempt to reach an agreement, they move in the opposite direction which will reduce the distance between them on the contested issues. While undergoing negotiation with contingent orders, if a new order arrives, it is difficult for the company to quote the due date and the price for new order. This is because the company cannot be sure at this stage whether agreement can be reached on orders involving ongoing negotiations. Also, while preparing quote for new order, more orders may arrive in the system within small time window for quotations. This will further complicate situation for the company on assigning the due dates and the prices for all the new orders. As it is believed that customer prefers early delivery of an order at a cheaper price, in such situation, the company must try to minimize the average due dates and prices to be quoted to the customers by taking into account the possible outcome of negotiations with the contingent orders. But no quotation should be so ludicrous that they will send the company bankrupt or tarnish its reputation merely for the sake of appeasing customers.

This paper assumes above problem in a flow shop environment consisting of various work centers. An order consists of batch of one product type that will enter from the initial work center and exit through the last work center. Each order involves operations at all the work centers. The paper aims at providing company with a capability to manage contingent orders while generating quotes for multiple customers simultaneously, without compromising on profits they expect to achieve. For the purpose, following assumptions are considered.

i) There would be at least one offer from the company and one counter-offer from all the contingent orders when the new orders arrive.

ii) There are many factors that affect the length of negotiation (Bac, 2001). Before negotiation begins, the negotiating parties may basically fix a deadline for negotiation or the number of negotiation rounds. Based on this, it is assumed that the maximum rounds of negotiation $(R)$ with contingent orders would be defined before starting negotiation.

iii) All the orders accumulated within period $\left\{t_{z},(t+1)_{z}\right\}$ will be processed at period $(t+1)$.

\section{Proposed Method}

The proposed method can be explained by two steps; steps 1 and 2. These steps will be utilized to manage the contingent orders and prepare quotes for the new orders respectively.

\section{Step 1: Managing contingent orders}

To offset the effect of contingent orders on quotation, Piya et al. (2009b) proposed a method to classify these orders into different sets, namely negotiation set and rejection set. Proposed method is based on the statistical data on acceptance probability of orders that arrived in the past. The major shortcoming of this method is the subjective nature of standard deviation. If its value is very high or low, the method will 
either classify all the contingent orders into negotiation set or rejection set. To overcome above shortcoming, this paper proposes new method that helps select best contingent orders in terms of expected contribution and acceptance probability. As shown in equation (1), the objective here is to find the combination and processing sequence of confirmed and contingent orders such that their expected contribution and acceptance probability lies at the minimum distance from the maximum expected contribution and acceptance probability.

$$
\min D=\left\{\left(Z_{\max }-Z^{s}\right)^{2}+\left(A_{\max }-A^{s}\right)^{2}\right\}^{\frac{1}{2}}
$$

To define the maximum expected contribution $Z_{\max }$, at first, expected contribution $Z^{s}$ for each combination and processing sequence of confirmed and contingent orders is calculated by Eq. (2). The expected contribution consists of selling price, production cost and acceptance probability.

\section{Nomenclature}

Index

$o:$ Order $(o=1,2, \ldots . ., O) ; c, k, n, l$

$c$ : Confirmed order

$k$ : Contingent order,

$n$ : New order

l: Latest accepted order

$t$ : Time/ period $\left(t=t_{e}, t_{s}, t_{z}, t_{o}\right)$

$t_{e}$ : End of the period $t$

$t_{s}$ : Start of period $t$

$t_{z}:$ Any time within period $t$

$j$ : Issues $\in$ due date $(d)$, price $(p) \quad r$ : Rounds of negotiation $(r=1, \ldots, ., R)$

$i$ : Operation $(i=1, \ldots \ldots, I) \quad f$ : Unit in the order $(f=1,2, \ldots . ., F)$

$m$ : Machine $(m=1, \ldots, M) \quad g$ : Processing sequence of new orders $(g=1,2, \ldots ., G)$

$s$ : Processing sequence of confirmed and contingent orders $(s=1,2, \ldots, S)$

\section{Variable}

$D$ : Distance

$A^{s}$ : Acceptance probability of sequence $s$

$\lim _{j o}$ : Limit level on issue $j$ of order $o$

$w_{j}^{c}$ : Expected weight of customer on issue $j$

$\operatorname{prod}_{o}$ : Total production time of order $o$

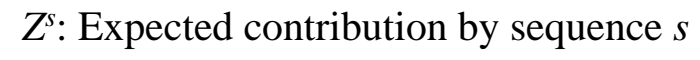

$Z_{\max }$ : Maximum expected contribution

$Q_{j o}$ : Quoted value on issue $j$ of order $o$

Prod $_{o}$ : Total cost of producing order $o$

$v_{j}: 0$ when $Y_{j o r}=\lim _{j o} ; 1$ otherwise

$\left(A_{o r}\right)^{s}$ : Acceptance probability for $r$ negotiation round of order $o$ with sequence $s$

$\left(X_{j o r}\right)^{s}$ : Offer on issue $j$ for $r$ negotiation round of order $o$ with sequence $s$

$Y_{\text {jor: }}$ : Counter-offer on issue $j$ for $r$ negotiation round of order $o$

$h_{o}^{s}$ : Inventory holding cost of order with sequence $s$ ( $h_{o}^{s} \in h_{o}^{I P} ;$ In process, $h_{o}^{F G I}$; Finished goods)

$E R_{\text {oif }} / C T_{\text {oif }}$ : Earliest release date/ Completion time for the operation $i$ and unit $f$ of order $o$ 


\section{Parameter}

$q_{o}$ : Total units in the order $o$

$R M_{o}$ : Raw material cost for order $o$

capm: $_{m}$ Capacity of machine $m$

$N$ : Total new orders

$\alpha$ : Smoothing constant

$W l(t)$ :Workload at time $t$

$g_{\text {first: Fist order in a sequence } g}$

Slast: Last order in a sequence $s$

$i_{\text {max: }}$ Operation with maximum processing time

$C d_{j o}$ : Cumulative difference on issue $j$ of order $o$
$A_{\text {max: }}$ Maximum acceptance probability

$S U_{o i}$ : Set up cost for $i$ operation of order $o$

$p_{o i}$ : Processing time for $i$ operation of order $o$

$P_{o i}$ : Cost of processing operation $i$ of order $o$

$w_{j}$ : Weight assigned to issue $j$ by the company

$\lambda_{o}$ : Profit margin coefficient of order $o$

$N M_{j o}$ : Negotiation margin on issue $j$ of order $o$

$a_{j o}$ : agreed value on issue $j$ of order $o$

$p_{o}$ : Price of order o

$\delta_{o r}$ : Aspiration level of order $o$ at $r$ negotiation round

$$
Z^{S}=\sum_{o \in c, k}\left\{\left\{q_{o}\left(X_{p o r}\right)^{s}-\left[\left(\sum_{i=1}^{I} S U_{o i}+q_{o} R M_{o}+q_{o} \sum_{i=1}^{I} p_{o i} P_{o i}\right)+h_{o}^{S}\right]\right\}\left(A_{o r}\right)^{s}\right\}
$$

i) Selling price $\left(X_{p o r}\right)^{s}$ : The selling price of confirmed order, for any sequence $s$, will be fixed and equal to the agreed price $\left(p_{o}\right)$.

However, the selling price for the contingent order will be equal to the price that can be offered to the customer for the next round of negotiation. Basically, it depends on the strategy of negotiation used by the manufacturer. As proposed by Piya et al. (2009b), selling price will be calculated by considering a linear trade-off relationship between the due date and the price at a fixed aspiration level. Aspiration level here represents a level of benefit sought by the company for a particular round of negotiation (Cakravastia \& Nakamura, 2002).

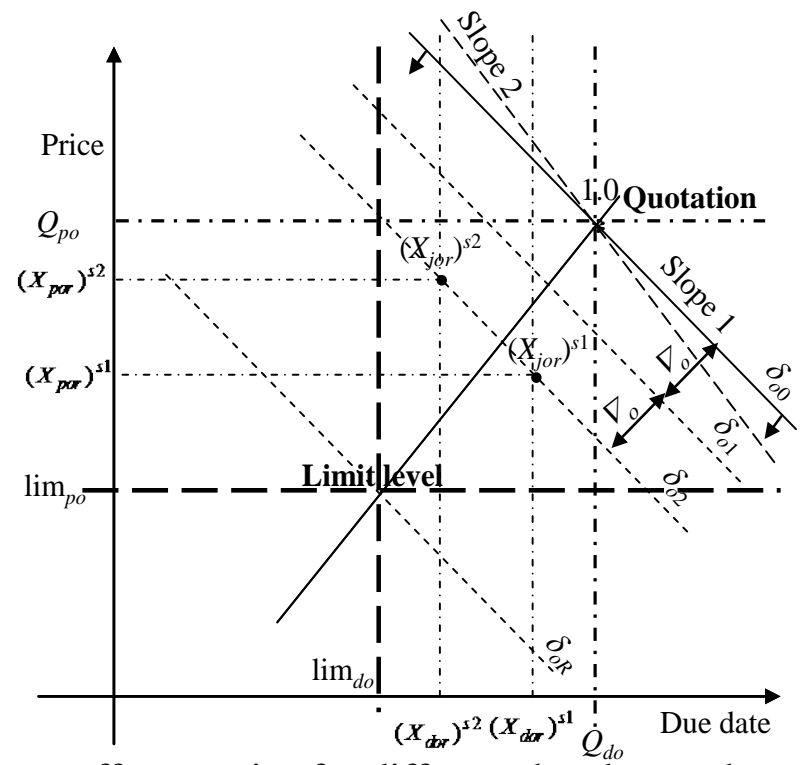

Fig. 1. Different new offer on price for different due date at the same aspiration level

Let the point $\left(Q_{d o}, Q_{p o}\right)$ in Fig. 1 be the point of quotation for contingent order $o$ and let the aspiration level at this point be the maximum aspiration level, $\delta_{00}$, of company. Normalizing this point and the point of limit level $\left(\lim _{d o}\right.$, $\lim _{p o}$ ) within $(1,0)$ and reducing aspiration level with the progress of negotiation by a fixed step size to approach nearer to the counter-offer of customer, aspiration level at any round can be 
calculate by Eq. (3).

$$
\delta_{o r}=\delta_{o(r-1)}-\frac{\left(\delta_{o 0}-\delta_{o R}\right)}{R}
$$

As the completion time of contingent order will be different for the different combination and processing sequence $s$ of confirmed and contingent orders, the price $X_{\text {por }}$ in equation (2) for contingent order depends on $X_{d o r}$. Suppose, by sequence $s 1$, if the due date of contingent order is $\left(X_{d o r}\right)^{s 1}$ in Fig. 1 , then $\left(X_{p o r}\right)^{s 1}$ will be the price that will be offered if the aspiration level for round $r$ is $\delta_{o 2}$. Based on this concept, the selling price for contingent order is given by the following equation.

$$
\left(X_{p o r}\right)^{s}=\frac{1}{w_{p}}\left[\delta_{o r}\left(Q_{p o}-\lim _{p o}\right)-\frac{w_{d}\left\{\left(X_{d o r}\right)^{s}-\lim _{d o}\right\}\left(Q_{p o}-\lim _{p o}\right)}{\left(Q_{d o}-\lim _{d o}\right)}\right]+\lim _{p o} \quad, \forall o \in k
$$

From above equation, it can be noted that the price $\left(X_{p o r}\right)^{s}$ also depends on the weight assigned by the company $\left(w_{j}\right)$ on the given issue. The weight affects the slope of aspiration level (Piya et al., 2010).

The details on the method for calculating the limit level $\left(\lim _{j o}\right)$ and quotation $\left(Q_{j o}\right)$ on the two issues will be discussed in step 2 of proposed method.

ii) Production cost: Production cost consists of set up cost, raw material cost, cost of processing the order and inventory holding cost. Except inventory holding cost, all the other costs are fixed.

$$
h_{o}^{S}=\sum_{i=1}^{I} \sum_{f=1}^{F}\left(E R_{O(i+1) f}-C T_{o i f}\right) h_{o}^{I P}+\sum_{f=1}^{F}\left\{\left(X_{d o r}\right)^{S}-C T_{\text {oIf }}\right\} h_{o}^{F G I}
$$

As shown in Eq. (5), both in process (IP) and finished good (FGI) inventory holding cost makes up the total cost of carrying inventory. For contingent orders, FGI cost will not be affected by the processing sequence as it is assumed that, during the negotiation process with contingent order, the order will be delivered to the customer as soon as its processing is completed. On the other hand, for confirmed orders both IP cost and FGI cost depends on the order processing sequence $s$.

The earliest release date and completion time in Eq. (5) can be calculated by using iterative method that considers precedence relationship between the operations of order and the shop floor information.

iii) Acceptance probability $\left(A_{o r}\right)^{s}$ : To calculate the probability of customer accepting a quotation submitted by the company, Easton and Moodie (1999) and Cakravastia and Takahashi (2003) have used an S-shaped logit model. This model was constructed without utilizing any information on contingent order. In the negotiation process, it is possible to obtain information on negotiating issues from the customer of contingent order. Use of such information will increase the authenticity of calculated acceptance probability. Proposed method utilizes information such as counter-offer on due date and price received from the customer, along with the due date and price that can be offered by the company, to calculate the acceptance probability of contingent orders. Therefore, acceptance probability here indicates the probability that the new offer of company will be accepted by the customer of contingent order.

$$
\left(A_{o r}\right)^{s}=\left\{\exp \sum_{j \in d, p}\left[w_{j}^{c}\left\{v_{j} \frac{\left(X_{j o r}\right)^{s}\left(\lim _{j o}-Y_{j o r}\right)}{\lim _{j o}\left(Q_{j o}\right)}\right\}^{\left(1-\frac{r-1}{R}\right)}\right]\right\}^{-1}, \forall o \in k
$$

If the counter-offer, $Y_{j o r}$, on any issue is more than or equal to the limit level, lim ${ }_{j o}$, the binary variable $v_{j}$ in Eq. (6) will be 0, thus resulting in an acceptance probability equal to 1 . This is because the limit level 
in this research indicates the level at which the company is willing to accept the order. From the equation note that the acceptance probability will be different for different rounds of negotiation $r$. It depends on the latest counter-offer of customer, the offer that will be submitted next by the company, the expected weight of customer on different issues and the remaining rounds of negotiation. It should be noted that the acceptance probability for confirmed order will be equal to 1 . For the method to calculate expected weight of customer in Eq. (6), refer to Piya et al. (2010). After calculating expected contribution for all the possible combination and sequence of confirmed and contingent orders, the expected contribution that has the highest value will be selected as the maximum expected contribution $Z_{\max }$ in Eq. (1).

$$
Z_{\text {max }}=\max \left(Z^{s}\right)
$$

Next, the acceptance probability of sequence $s$ in Eq. (1) is calculated by taking the product of acceptance probability of all the orders that is included in the given sequence.

$$
A^{s}=\prod_{o=1}^{O}\left(A_{o r}\right)^{s}, \quad \forall o \in c, k
$$

The maximum acceptance probability $\left(A_{\max }\right)$ in equation $(1)$ can be directly assigned the value of 1.0. This is because acceptance probability for the combination of only confirmed orders with any sequence $s$ will be 1.0.

As discussed before, the expected contribution and acceptance probability will be calculated for each combination and processing sequence of confirmed and contingent orders. The number of combinations will be equal to $2^{k}$ and for each combination the possible sequence will be equal to $(k+c)$ !. It means that even for small problem instance, the possible combination and sequence will be very large. To avoid generation of such large combinations, two important constraints are employed.

$$
\begin{aligned}
& \lim _{d o} \leq C T_{\text {oIF }} \leq d_{o}, \quad \forall o \in C \\
& X_{d o r}^{s} \geq \max \left(\lim _{d o}, C T_{\text {oIF }}\right), \quad \forall o \in k
\end{aligned}
$$

Constraint in Eq. (9) indicates that the completion time of confirmed order should be greater than or equal to its limit level on due date and less than or equal to agreed due date. Similarly, constraint in Eq. (10) indicates that the new offer on due date should be more than or equal to the maximum value between its limit level on due date or completion time. Other constraints include the precedence constraint, capacity constraint and constraint on total weight as indicated by Eq. (11), Eq. (12) and Eq. (13), respectively.

$$
\begin{aligned}
& E R_{o(i+1) f} \geq C T_{o i f}, \quad \forall i, \forall f, \forall o \in c, k \\
& \sum_{o \in c, k} \sum_{i=1}^{I}\left(p_{o i}\right)_{\left\{t_{z},(t+1)_{z}\right\}} \leq \sum_{m=1}^{M}\left(\operatorname{cap}_{m}\right)_{\left(t_{s}, t_{e}\right)} \\
& \sum_{j \in d, p} w_{j}=1
\end{aligned}
$$

\section{Step 2: Generating quotes}

Step 1 helps identify the set of confirmed and contingent orders, with their processing sequence, which gives the maximum expected contribution and acceptance probability. The result of step1 is then used in step 2. From here onwards, sequence $s$ means the sequence obtained for confirmed and contingent orders in step 1 and $k$ represents only those contingent orders that are included in the sequence $s$. The objective of step 2 is to minimize the average of due dates and prices to be quoted to the multiple new customers. As shown in Eq. (14), the average of quoted values on two issues i.e., the due dates and the prices are 
integrated by vector normalization method (Van \& Nijkamp, 1977).

$$
\begin{gathered}
\min V=\sum_{j \in d, p} \frac{\operatorname{Avg}\left(Q_{j o}\right)^{g}}{\left[\sum_{g=1}^{G}\left\{\operatorname{Avg}\left(Q_{j o}\right)^{g}\right\}^{2}\right]^{\frac{1}{2}}}, \forall o \in n \\
\operatorname{Avg}\left(Q_{j o}\right)^{g}=\frac{\sum_{o=1}^{O}\left(Q_{j o}\right)^{g}}{N}, \quad \forall o \in n
\end{gathered}
$$

Sequence $g$ in Eqs. (14) means the sequence of new orders. The starting time of sequence $g$ will be equal to the completion time of sequence $s$. It means that the model considers all the possible sequence $g$ of new orders, at fixed sequence $s$ of confirmed and contingent orders, to find the minimum value of $V$. As shown in Eq. (16), the quoted value on issue $j$ consists of limit level and negotiation margin on the given issue. It will be different for the different processing sequence $g$ of new orders.

$$
\left(Q_{j n}\right)^{g}=\left(\lim _{j n}\right)^{g}+\left(N M_{j n}\right)^{g}
$$

i) Limit Level (lim $\left.{ }_{j n}\right)$ : Limit level represents the level below which company will not negotiate with customers on either issues i.e., due date and price.

(a) Due date: The limit level on due date, $\lim _{d n}$, is the date below which it is not possible to complete the processing of an order. It is calculated by subtracting the completion time of new order at given sequence $g$ with the product of probability of rejection and the total production time of contingent orders.

$$
\left(\lim _{d n}\right)^{g}=\left(C T_{n i F}\right)^{g}-\left[1-A^{s}\right] \sum_{o \in k} \operatorname{prod}_{o}
$$

Completion time of new order in Eq. (17) depends on its position in the sequence $g$. As shown in Eq. (18), if the position of new order lies in the beginning of sequence $g$, the completion time will be the summation of its total production time and the completion time of first operation of order $o$ that lies at the end of sequence $s$. Otherwise, it will be the summation of its total production time and the completion time of first operation of other new order whose position lies before order $n$ in the sequence $g$.

$$
\begin{aligned}
& \left(C T_{n i F}\right)^{g_{\text {first }}}=\left(C T_{\text {oif }}\right)^{s_{\text {last }}}+\operatorname{prod}_{n}, \forall o \in c, k \\
& \left(C T_{n i F}\right)^{g_{\text {nth }}}=\left(C T_{n i f}\right)^{g_{\text {nth-1 }}+\operatorname{prod}_{n}}
\end{aligned}
$$

The total production time in the Eq. (17), Eq. (18), and Eq. (19) can be calculated based on the operation of order with the maximum processing time. As shown in Eq. (20), the first and second portions at the right hand side of equation are used to calculate the processing time without including service delays. However, the third and fourth portions add on the respective service delays before and after operation with maximum processing time. Service delays incurs if machine on which operation of an order is to be performed is occupied by the operation of any other order.

$$
\operatorname{prod}_{o}=\left(q_{o}-1\right) \max _{i} p_{o i}+\sum_{i=1}^{I} p_{o i}+\sum_{i=1}^{i_{\max }-1}\left(E R_{o(i+1) 1}-E R_{o i 1}-p_{o i}\right)+\sum_{i=1}^{i_{\max }+1}\left(C T_{o i F}-C T_{o(i-1) F}-p_{o i}\right)
$$

b) Price: The limit level on price, $\lim _{p n}$, indicates the price at which company wishes to reach an agreement after negotiation. As shown in Eq. (21), it consists of production cost $\left(\operatorname{Prod}_{n}\right)$, and profit margin coefficient $\left(\lambda_{n}\right)$.

$$
\begin{aligned}
& \left(\lim _{p n}\right)^{g}=\left(\operatorname{Prod}_{n}\right)^{g}\left(1+\lambda_{n}\right) \text { where, } \\
& \left(\operatorname{Prod}_{n}\right)^{g}=\sum_{i=1}^{I} S U_{n i}+q_{n} R M_{n}+q_{n} \sum_{i=1}^{I} p_{n i} P_{n i}+\left(h_{n}^{I P}\right)^{g} \sum_{i=1}^{I} \sum_{f=1}^{F}\left(E R_{n(i+1) f}-C T_{n i f}\right)+\left(h_{n}^{F G I}\right)^{g} \sum_{f=1}^{F}\left\{\left(Q_{d n}\right)^{g}-C T_{n i f}\right\}
\end{aligned}
$$

The production cost of new order includes set up cost, raw material cost, cost of processing the order and the inventory holding costs. Here also, except in process and finished goods inventory holding cost all 
the other costs are fixed and is unaffected by the sequence $g$. Profit margin coefficient in Eq. (21), $\lambda_{n}$, adds some profit margin to the production cost. In the proposed research, it is assumed that the profit margin of company will be the function of expected workload in the system and the expected number of competitors. Equations for calculating profit margin coefficient are similar to Piya et al. (2009b) except for the calculation of expected workload. Eq. (23) indicates the summation, within a time frame of $\left(t_{s}\right.$, $t_{e}$ ), of workload of all the confirmed orders, expected workload of contingent orders and the total processing time of new orders to calculate the expected workload.

$$
W l(t)=\left[\sum_{o \in c i=1}^{I}\left(C T_{o i F}-E R_{o i 1}\right)+A^{s} \sum_{o \in k i=1}^{I}\left(C T_{o i F}-E R_{o i 1}\right)+\sum_{o \in n}\left(q_{o} \sum_{i=1}^{I} p_{o i}\right)\right]
$$

ii) Negotiation margin $\left(N M_{j n}\right.$,): The negotiation margin provides company with an allowance to negotiate on the contested issues with the customer. Therefore, if the customer requested to reduce the value on the quoted due date and/or price, the company can do it without risking the chance of order being tardy and without reducing their desired profit margin. The concept of cumulative difference is utilized to calculate negotiation margin. As shown in Eq. (24), the cumulative difference along with the limit level on the given issue at sequence $g$ is used to calculate the negotiation margin for the given issue.

$$
\begin{aligned}
& \left(N M_{j n}\right)^{g}=\left[\frac{c d_{j n}}{\left(1-c d_{j n}\right)}\right]\left(\lim _{j n}\right)^{g} \\
& c d_{j n}=\alpha\left(\frac{Q_{j l}-a_{j l}}{Q_{j l}}\right)+(1-\alpha) c d_{j l}
\end{aligned}
$$

Cumulative difference is basically the cumulative information on the difference between the quoted and the agreed values on given issues related to the past orders. In equation (25), smoothing constant $(\alpha)$ represents the value company gives to latest information as compared to past information on agreement.

\section{Numerical Analysis}

The aim of numerical analysis is to show the working mechanism and effectiveness of proposed method.

Working mechanism: The analysis is carried out by considering 5 work centers with each center capable of performing specific task. Nine orders are generated with orders A, B and C as confirmed orders; orders $\mathrm{D}, \mathrm{E}$ and $\mathrm{F}$ are contingent orders and orders G, H and I are new orders for which quotations are to be prepared. The agreed due dates and prices of confirmed orders and the information on contingent orders necessary to calculate its acceptance probability are selected randomly as shown in Table 1 . Processing time, total units, set up cost, raw material cost, cost of processing the order and inventory holding costs are uniformly distributed within the value as shown in Table 2. The total number of negotiation rounds, current rounds of negotiation for entire contingent orders and the weights of manufacturer and customer for each issue are fixed at 5,3 and 0.5 respectively.

\section{Table 1}

Status of confirmed and contingent orders

\begin{tabular}{cccccccccc}
\hline Order status & Order & $d_{o}$ & $p_{o}$ & $Y_{\text {dor }}$ & $Y_{\text {por }}$ & $\lim _{\text {do }}$ & $\lim _{p o}$ & $Q_{\text {do }}$ & $Q_{p o}$ \\
\hline Confirmed order & $\mathrm{A}$ & 24 & 15000 & - & - & - & - & - & - \\
& $\mathrm{B}$ & 60 & 12000 & - & - & - & - & - & - \\
& $\mathrm{C}$ & 80 & 13800 & - & - & - & - & - & - \\
\hline Contingent order & $\mathrm{D}$ & - & - & 38 & 13000 & 45 & 18000 & 80 & 26000 \\
& $\mathrm{E}$ & - & - & 34 & 10000 & 38 & 12500 & 74 & 21000 \\
& $\mathrm{~F}$ & - & - & 40 & 12000 & 42 & 14000 & 88 & 23000 \\
\hline
\end{tabular}

\section{Table 2}

Value of other parameters considered in the analysis

\begin{tabular}{ccccccc}
\hline $\begin{array}{c}p_{o i} \\
\text { (Units) }\end{array}$ & $\begin{array}{c}q_{o} \\
\text { (Time unit) }\end{array}$ & $\begin{array}{c}S U_{o i} \\
(\$)\end{array}$ & $\begin{array}{c}R M_{o} \\
(\$)\end{array}$ & $\begin{array}{c}P_{o i} \\
(\$)\end{array}$ & $\begin{array}{c}h_{o}^{I P} \\
(\$)\end{array}$ & $\begin{array}{c}h_{o}^{F G I} \\
(\$)\end{array}$ \\
\hline$U(2,5)$ & $U(2,4)$ & $U(1000,1750)$ & $U(2500,3200)$ & $U(100,125)$ & $U(50,80)$ & $U(80,120)$ \\
\hline
\end{tabular}




\section{Step 1: Managing contingent orders}

The analysis will first show the method of selecting contingent orders and its sequence with confirmed orders such that the objective of step 1 is accomplished. To manage the contingent orders, at first, proposed method elaborates all the possible combinations and sequences of confirmed and contingent orders for the given problem. Satisfying constraints in Eq. (9) and Eq. (10) fourteen different sequences are possible which are as shown in Table 3. Next, the due date and the price that can be submitted as a new offer in the next round i.e., $\left(X_{d o r}, X_{\text {por }}\right.$ ), is calculated for each contingent orders available in the given sequence. For example, for order D in the sequence A-B-C-D, the completion time will be equal to 51 . The price for this completion time can be calculated by using Eq. (4).

$X_{\text {por }}=\frac{1}{0.5}\left[0.6(26000-18000)-\frac{0.5(51-45)(26000-18000)}{(80-45)}\right]+18000=\$ 23,028$

Aspiration level for round 3 in the above equation i.e., 0.6 is obtained by using Eq. (3). The acceptance probability of this offer is then calculated by Eq. (6).

$$
A_{o r}=\left\{\exp \left[0.5\left\{1.0 \frac{51(45-38)}{45(80)}\right\}^{\left(1-\frac{3-1}{5}\right)}+0.5\left\{1.0 \frac{23028(18000-13000)}{18000(26000}\right\}^{\left(1-\frac{3-1}{5}\right)}\right]\right\}^{-1}=0.725 \%
$$

Next, identifying fixed processing cost and inventory holding cost based on the given sequence, the expected contribution of an order is computed by Eq. (2). Then, summing the expected contribution of all the orders in the sequence will gives value of $Z^{s}$ as shown in Table 3. From the table, it is seen that the maximum expected contribution, $Z_{\max }$, is obtained for the sequence A-B-C-E-D-F. The acceptance probability $A^{s}$ in Table 3 is calculated by taking the product of acceptance probability of all the orders in the sequence. For the example A-B-C-D, the acceptance probability of this sequence is calculated as shown below.

$A^{s}=(1 \mathrm{x} 1 \mathrm{x} 1 \mathrm{x} 0.725)=0.725 \%$.

As the unit of $Z^{s}$ and $A^{s}$ is different, the value of $Z^{s}$ is first normalized by equating $Z_{\max }$ with 1.0 and minimum $Z^{s}$ with 0 . Then, by considering normalized value of $Z_{\max }, Z^{s}, A_{\max }$ and $A^{s}$, the distance $D$ is calculated by Eq. (1). From Table 3 it is evident that the minimum distance is obtained for the sequence A-B-C-F-D.

\section{Table 3}

Results obtained from step 1

\begin{tabular}{|c|c|c|c|c|c|c|}
\hline Sequence & $Z_{S}(\$)$ & $Z_{\max }$ & $A_{s}(\%)$ & $A_{\max }$ & $\operatorname{Norm}(Z s)$ & Distance D \\
\hline A-B-C & 115769 & & 1.0 & & 0 & 0.762 \\
\hline A-B-C-D & 146620 & & 0.725 & & 0.328 & 0.725 \\
\hline A-B-C-D-E & 169094 & & 0.554 & & 0.567 & 0.621 \\
\hline A-B-C-D-E-F & 206573 & & 0.466 & & 0.965 & 0.535 \\
\hline A-B-C-E & 121167 & & 0.756 & & 0.157 & 0.973 \\
\hline A-B-C-E-D & 172344 & 209808 & 0.545 & 1.0 & 0.601 & 0.604 \\
\hline A-B-C-E-D-F & 209808 & & 0.46 & & 1.000 & 0.540 \\
\hline A-B-C-F & 146932 & & 0.85 & & 0.331 & 0.685 \\
\hline A-B-C-F-E & 170568 & & 0.65 & & 0.582 & 0.544 \\
\hline A-B-C-F-E-D & 207669 & & 0.46 & & 0.977 & 0.540 \\
\hline A-B-C-D-F & 190005 & & 0.61 & & 0.789 & 0.443 \\
\hline A-B-C-F-D & 190217 & & 0.63 & & 0.792 & 0.424 \\
\hline A-B-C-E-F & 172223 & & 0.64 & & 0.600 & 0.537 \\
\hline
\end{tabular}


To generate quotes on due dates and prices, at first, the possible sequence of new orders with sequence A-B-C-F-D obtained in step 1 is elaborated. For new orders G, H and I there will be total of six sequences as shown in Table 4.

Table 4

Results obtained for different sequences

\begin{tabular}{ccccc}
\hline Sequence & Avg $Q_{\text {do }}$ & Avg $Q_{\text {po }}$ & $V$ & Min $V$ \\
\hline A-B-C-F-D-G-I-H & 153 & 28086 & 0.824 & 0.829 \\
A-B-C-F-D-G-H-I & 159 & 28136 & 0.793 & 0.793 \\
A-B-C-F-D-I-G-H & 133 & 27745 & 0.822 & 0.826 \\
A-B-C-F-D-I-H-G & 148 & 27986 & 0.831 \\
A-B-C-F-D-H-G-I & 156 & 28038 & 28149 & \\
A-B-C-F-D-H-I-G & 151 & &
\end{tabular}

Then, the limit level on due date of each new order in the sequence is calculated. For example, for order $\mathrm{G}$ in the sequence A-B-C-F-D-G-I-H, completion time is 101 time units. Therefore,

$\lim _{d G}=101-\{(1-0.63) \times 56\}=81$

In the above equation, 0.63 is the acceptance probability of sequence A-B-C-F-D and 56 is the total processing time of contingent orders $\mathrm{D}$ and $\mathrm{F}$.

Next, the negotiation margin is calculated by Eq. (24). For the purpose, the cumulative difference is assumed to be 0.35 .

$N M_{d G}=\{0.35 /(1-0.35)\} 81=38$

Then, by summing the negotiation margin with the limit level, the due date that can be quoted for order $\mathrm{G}$ in this sequence will be 124 time units. Similarly, calculating the due dates for orders I and $\mathrm{H}$ and taking their average will gives 153 as shown in Table 4.

Next, calculate the limit level on prices that can be quoted to the new orders. Assuming $\lambda_{n}$ as 0.30 ,

$\lim _{p G}=14167(1+0.30)=\$ 18417$

In the above equation, 14167 represent the cost of producing order $\mathrm{G}$ with the sequence A-B-C-F-D-G$\mathrm{I}-\mathrm{H}$. Then, using the concept similar to calculating negotiation margin on due date, the negotiation margin on price for order $\mathrm{G}$ is $\$ 9916$. Summing the negotiation margin with the limit level, the price that can be quoted for order $\mathrm{G}$ in this sequence will be $\$ 28333$. Similarly, calculating the prices for orders I and $\mathrm{H}$ and taking their average will gives $\$ 28086$ as shown in Table 4.

After obtaining the average values on $Q_{j o}$ for all the sequences $g$, the average on due dates and prices of each sequence is then integrated by Eq. (14) which are as shown by the fourth column of Table 4. From the table, it can be noticed that the sequence A-B-C-F-D-I-G-H gives the minimum value of $V$. Therefore, the due dates and prices corresponding to this sequence of new orders will be quoted to the customers $\mathrm{G}$, $\mathrm{H}$ and $\mathrm{I}$.

Comparing proposed method with sequential quotation: The proposed method is then compared with sequential method of quotation in terms of production cost, average quoted due date and price, and computational time to solve the problem. In the sequential method, quotation is generated for each order one by one, independent of other new orders. For this method also, step 1 is utilized to manage contingent orders. However, the major difference will be in a way quotation is generated in step 2. For the comparison several test problems are generated by taking various combinations of new orders with confirmed and contingent orders as shown in Table 5. In Table 5, at column one, the first and second elements $(3 \times 3)$ representing confirmed and contingent orders respectively for all test instances are same. The reason is that these two elements will not have any effect on the result between sequential and simultaneous methods of quotations because for both the methods step 1 i.e., managing contingent orders 
is same. All the information's related to these orders are similar to Table 1 and Table 2 . The third element in test instances column of Table 5 represents new order for which quotations need to be prepared. Processing time, number of units and all the necessary costs for new orders are also generated by using information's in Table 2. For each test problem five replications are generated with the set up as mentioned above and conduct the analysis. The results obtained from these replications are then aggregated to obtain the average result. All test codes are executed using Matlab program of version 7.9.0 R2009b on an Intel@ ${ }^{\circledR}$ Core $^{\mathrm{TM}} 2$ Quad CPU @ 3.00 GHz with 4.00 GB RAM.

Table 5

Sequential verses simultaneous method of quotation

\begin{tabular}{|c|c|c|c|c|c|c|c|c|}
\hline \multirow{2}{*}{$\begin{array}{c}\text { Test } \\
\text { instances }\end{array}$} & \multicolumn{4}{|c|}{ Sequential Quotation } & \multicolumn{4}{|c|}{ Simultaneous Quotation } \\
\hline & $\begin{array}{c}\text { Production } \\
\text { cost }(\$)\end{array}$ & $\begin{array}{l}\text { Avg. } Q_{d o} \\
(\$)\end{array}$ & $\begin{array}{l}\text { Avg. } Q_{p o} \\
(\$)\end{array}$ & $\begin{array}{l}\text { CPU time } \\
\text { (mins) }\end{array}$ & $\begin{array}{c}\text { Production } \\
\text { cost }(\$)\end{array}$ & $\begin{array}{l}\text { Avg. } Q_{d o} \\
(\$)\end{array}$ & $\begin{array}{l}\text { Avg. } Q_{p o} \\
(\$)\end{array}$ & $\begin{array}{l}\text { CPU time } \\
\text { (mins) }\end{array}$ \\
\hline $3 \times 3 \times 1$ & 21150 & 45 & 23500.00 & 00:08:54 & 21150 & 45 & 23500.00 & 00:08:54 \\
\hline $3 \times 3 \times 2$ & 39015 & 72 & 21675.00 & 00:08:54 & 36835.2 & 64 & 20464.00 & 00:08:56 \\
\hline $3 \times 3 \times 3$ & 52515 & 93 & 19450.00 & 00:09:03 & 49749.3 & 85 & 18425.67 & 00:09:04 \\
\hline $3 \times 3 \times 4$ & 69345 & 112 & 19262.50 & 00:09:08 & 64333.8 & 100 & 17870.50 & 00:09:28 \\
\hline $3 \times 3 \times 5$ & 77422.5 & 131 & 17205.00 & 00:09:12 & 70642.8 & 117 & 15698.40 & 00:09:29 \\
\hline $3 \times 3 \times 6$ & 96826.5 & 149 & 17930.83 & 00:09:10 & 86882.4 & 132 & 16089.33 & $00: 19: 48$ \\
\hline $3 \times 3 \times 7$ & 119191.5 & 170 & 18919.29 & 00:09:18 & 104231.7 & 142 & 16544.71 & $00: 36: 38$ \\
\hline $3 \times 3 \times 8$ & 133980.3 & 192 & 18608.38 & 00:09:24 & 116686.8 & 158 & 16206.50 & 01:12:08 \\
\hline $3 \times 3 \times 9$ & 154122.3 & 215 & 19027.44 & 00:09:32 & 132109.2 & 181 & 16309.78 & 01:56:12 \\
\hline $3 \times 3 \times 10$ & 178872.3 & 237 & 19874.70 & 00:09:34 & 153078.3 & 195 & 17008.70 & $02: 52: 23$ \\
\hline
\end{tabular}

From Table 5, it can be observed that simultaneous method outperform sequential method of quotation in terms of all the measure of performance except computational timing. The main reason for the result is the ability of simultaneous method to coordinate the processing sequence among new orders. It helps to complete processing of orders early. Also, due to this, the cost of carrying inventory will be less which in turn will reduce the production cost. Since the average of due dates and prices to be quoted to the customers is less, the average probability of quotations getting accepted will be more by simultaneous method as compared to sequential method. Fig. 1 shows the relationships between the differences on quoted values by sequential and simultaneous methods with respect to number of new orders. From the figure it is evident that as the number of new orders increases, the difference on the quoted values on due date and price between two methods will increase. It means that more the new orders to be quoted better will be to use simultaneous method of quotation.

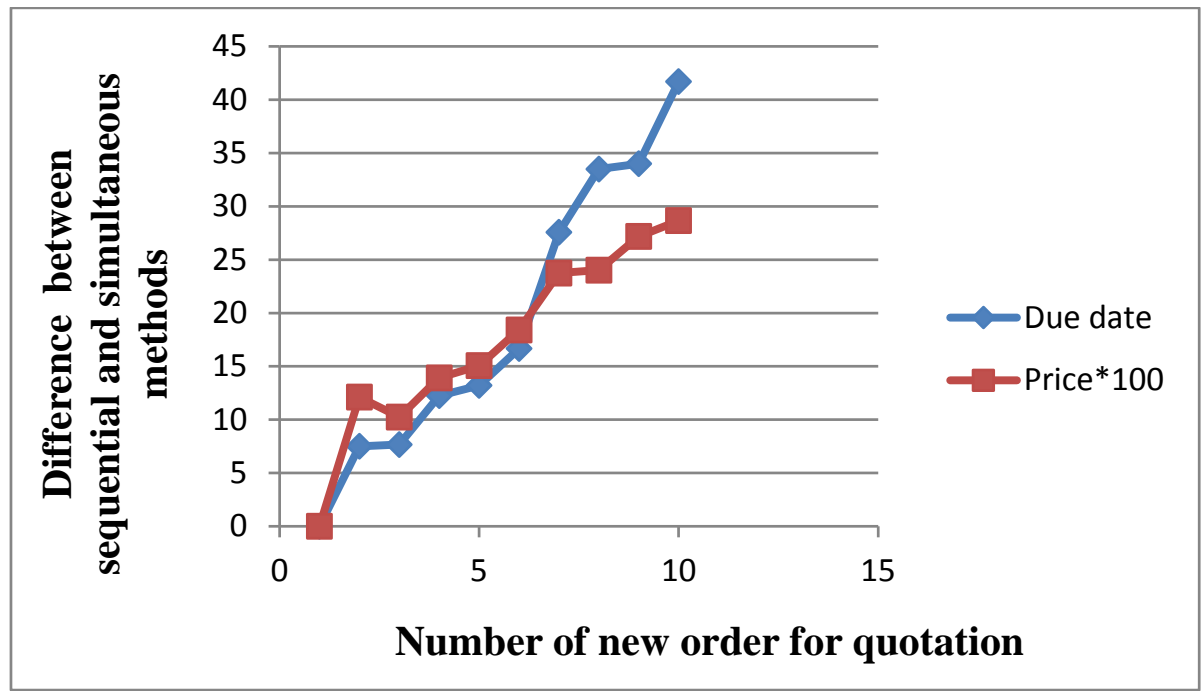

Fig. 1. Relationship between number of new order and difference of quoted values

However, in terms of computation timing, sequential method is better than simultaneous method. This is 
due to the reason that the number of possible solution/ sequence in simultaneous methods will be more by $(n !-1)$ than by sequential method. For sequential method the major computation timing is needed to carry out step 1 i.e., to manage contingent orders. Otherwise, the possible solution for each new order, at each iteration, will only be 1 . However, for simultaneous method it increases exponentially with the increase in the number of new orders. Addition of some constraints for step 2, as in step 1, might helps reduce the no of possible solution considerably which in turn will reduce computation timing for simultaneous method.

\section{Conclusions}

This paper proposed two steps method to counter the uncertainty caused by contingent orders while preparing quotes for multiple new customers simultaneously. The first step helps manage the effect of contingent orders on quotation being submitted to the new customers. While, second steps help generate quotes for multiple customers simultaneously. Integrated probabilistic and negotiation theories are introduced to offset the effect of contingent orders on quotations. Numerical analysis demonstrated that, except for computational time, proposed method outperform sequential method of quotation on all measure of performances. Therefore, it can be concluded that in contrast to the sequential method, proposed method improves the overall acceptance probability of quotations being submitted to the multiple customers, without diminishing the profit margin of company. This can be attributed to the capability of simultaneous method to reduce the cost and time of production by streamlining the processing of multiple new orders with confirmed and contingent orders. As a future research expansion, the proposed method can be integrated with the simultaneous negotiation mechanism within OA decision framework. Also, as evident from the numerical analysis, even for small to medium size problem the computational time to solve the problem for simultaneous method is high. Therefore, to solve large size industrial problem there is a need to implement intelligent method such as heuristic/ meta-heuristic to reduce computational timing for simultaneous method of quotation.

\section{References}

Bac, M. (2001). On creating and claiming value in negotiations. Group Decision and Negotiation, 10(3), 237-251.

Baker, K. R. (1984). Sequencing rules and due-date assignments in a job shop. Management science, 30(9), 1093-1104.

Bertrand, J. W. M. (1983). The effect of workload dependent due-dates on job shop performance. Management Science, 29(7), 799-816.

Cakravastia, A., \& Nakamura, N. (2002). Model for negotiating the price and due date for a single order with multiple suppliers in a make-to-order environment. International journal of production research, 40(14), 3425-3440.

Cakravastia, A., \& Takahashi, K. (2003). Integrated bidding and manufacturing planning decisions with contingent orders in a make-to-order environment. Journal of JIMA, 54(5), 291-301.

Chaharsooghi, S. K., Honarvar, M., Modarres, M., \& Kamalabadi, I. N. (2011). Developing a two stage stochastic programming model of the price and lead-time decision problem in the multi-class maketo-order firm. Computers \& Industrial Engineering, 61(4), 1086-1097.

Chand, S., \& Chhajed, D. (1992). A single machine model for determination of optimal due dates and sequence. Operations Research, 40(3), 596-602.

Charnsirisakskul, K., Griffin, P. M., \& Keskinocak, P. (2006). Pricing and scheduling decisions with leadtime flexibility. European Journal of Operational Research, 171(1), 153-169.

Corti, D., Pozzetti, A., \& Zorzini, M. (2006). A capacity-driven approach to establish reliable due dates in a MTO environment. International Journal of Production Economics, 104(2), 536-554.

Easton, F. F., \& Moodie, D. R. (1999). Pricing and lead time decisions for make-to-order firms with contingent orders. European Journal of Operational Research, 116(2), 305-318. 
ElHafsi, M. (2000). An operational decision model for lead-time and price quotation in congested manufacturing systems. European Journal of Operational Research, 126(2), 355-370.

Enns, S. T. (1995). An economic approach to job shop performance analysis. International journal of production economics, 38(2-3), 117-131.

Kaminsky, P., \& Kaya, O. (2008). Scheduling and due-date quotation in a make-to-order supply chain. Naval Research Logistics (NRL), 55(5), 444-458.

Keskinocak, P., Ravi, R., \& Tayur, S. (2001). Scheduling and reliable lead-time quotation for orders with availability intervals and lead-time sensitive revenues. Management Science, 47(2), 264-279.

Lawrence, S. R. (1995). Estimating flowtimes and setting due-dates in complex production systems. IIE transactions, 27(5), 657-668.

Liu, L., Parlar, M., \& Zhu, S. X. (2007). Pricing and lead time decisions in decentralized supply chains. Management Science, 53(5), 713-725.

Moodie, D. R., \& Bobrowski, P. M. (1999). Due date demand management: negotiating the trade-off between price and delivery. International Journal of Production Research, 37(5), 997-1021.

Piya, S., Takahashi, K. \& Morikawa, K. (2009a), Introducing quotation and negotiation structure in the order acceptance decision model. International Journal of Operations and Quantitative Management, 15 (4), 293-318.

Piya, S., Takahashi, K., \& Morikawa, K. (2009b), Quotation and capacity planning with contingent orders in make-to-order system. Proceeding of $20^{\text {th }}$ International Conference on Production Research, Shanghai, China. (in CD-ROM).

Piya, S., Takahashi, K., \& Morikawa, K. (2010). Negotiation with Customer Priority and Dynamic Aspiration Level for Order Acceptance Decision. Australian Society for Operations Research Bulletin, 29 (4), 21-47.

Ragatz, G. L., \& Mabert, V. A. (1984). A framework for the study of due date management in job shops. The International Journal of Production Research, 22(4), 685-695.

Seidmann, A., \& Smith, M. L. (1981). Due date assignment for production systems. Management Science, 27(5), 571-581.

Shantikumar, J. G., \& Sumita, U. (1988). Approximations for the time spent in a dynamic job shop with applications to due-date assignment. The International Journal of Production Research, 26(8), 13291352.

Slotnick, S. A. (2011). Optimal and heuristic lead-time quotation for an integrated steel mill with a minimum batch size. European Journal of Operational Research, 210(3), 527-536.

Sujan, P., Takahashi, K., \& Morikawa, K. (2009). Introducing quotation and negotiation structure in the order acceptance decision model. International Journal of Operations and Quantitative Management, 15 (4), 293-318.

Van Delft, A., \& Nijkamp, P. (1977). Multi-criteria analysis and regional decision-making (Vol. 8). Springer.

Van Ooijen, H. P. G., \& Bertrand, J. W. M. (2001). Economic due-date setting in job-shops based on routing and workload dependent flow time distribution functions. International Journal of Production Economics, 74(1), 261-268.

Watanapa, B., \& Techanitisawad, A. (2005a). Simultaneous price and due date settings for multiple customer classes. European Journal of Operational Research, 166(2), 351-368.

Watanapa, B., \& Techanitisawad, A. (2005b). A genetic algorithm for the multi-class contingent bidding model. OR Spectrum, 27(4), 525-549.

Wein, L. M. (1991). Due-date setting and priority sequencing in a multiclass M/G/1 queue. Management Science, 37(7), 834-850.

Xianfei, J., Kunpeng, L., \& Appa, I.S. (2013). Scheduling and optimal delivery time quotation for the customers with time sensitive demand. International Journal of Production Economics, 145(1), 349358.

Zorzini, M., Corti, D., \& Pozzetti, A. (2008). Due date (DD) quotation and capacity planning in maketo-order companies: Results from an empirical analysis. International Journal of Production Economics, 112(2), 919-933. 